\title{
ESTRATEGIA TECNOLÓGICA EXPEDITIVA EN LA GESTION DE RECURSOS LITICOS DURANTE EL POSTGLACIAL. EL CASO DE CUEVA BURUCUYA (TANDILIA ORIENTAL, ARGENTINA)
}

\section{EXPEDITIVE TECHNOLOGICAL STRATEGY IN THE MANAGEMENT OF LITHIC RESOURCES DURING THE POSTGLACIAL. THE CASE OF CUEVA BURUCUYA (EAST TANDILIA, ARGENTINA)}

\author{
Gustavo Federico Bonnat ${ }^{1}$, Diana Leonis Mazzanti² \\ ${ }^{1}$ Laboratorio de Arqueología, Universidad Nacional de Mar del Plata, Av. J. B. Justo 2550 PB (7600) \\ Mar del Plata, Argentina. E-mail: fbonnat@hotmail.com \\ 2Laboratorio de Arqueología, Universidad Nacional de Mar del Plata, Av. J. B. Justo 2550 PB (7600), \\ Mar del Plata, Argentina. E-mail: arqueolab@gmail.com
}

Presentado: 30/09/2020 Aceptado: 01/4/2021

\section{Resumen}

En este trabajo se presentan y discuten los resultados surgidos del estudio de la tecnología lítica del sitio Cueva Burucuyá (Tandilia oriental) datado en ca. 12.700 años cal. AP. El sitio arqueológico fue definido como un campamento logístico de uso efimero donde se utilizaron principalmente las ortocuarcitas locales de la Formación Balcarce (OFB) para la manufactura de artefactos líticos, acompañadas por una variedad restringida de rocas procedentes de distintas escalas espaciales. Las OFB fueron identificadas en la mayoría de los instrumentos líticos y desechos de la talla, pudiéndose reconstruir todas las etapas de la cadena operativa. En otros sitios arqueológicos tempranos de la subregión Pampa húmeda, el uso de los recursos líticos estuvo orientado a otras rocas de mejor calidad para la manufactura de instrumentos y las OFB se presentan en menores porcentajes o no fueron usadas. No obstante, en el sector oriental de Tandilia estas rocas son el recurso local más abundante y fueron utilizadas con distinta intensidad en los sitios arqueológicos. Esta contribución aporta datos sobre el uso de los recursos líticos y pone especial atención en el desarrollo de un comportamiento tecnológico expeditivo en el abastecimiento y uso de las OFB.

Palabras claves: Región Pampeana, Tandilia, Pleistoceno tardío-Holoceno temprano, CazadoresRecolectores, Tecnología lítica.

\section{Abstract}

This paper presents and discusses the analysis of the lithic technology assemblage at the Cueva Burucuyá archaeological site (eastern Tandilia), dated at ca. 12.700 years cal. AP. The archaeological site 
was defined as a logistical field camp and the local orthoquarzites of Balcarce Formation (FBO) were the preferred used resource for lithic stone tools manufacture, while the other less common rocks, from different spatial scales, were used in a lower frequency. Furthermore, in other early archaeological sites from Pampa humid subregion, the use of lithic resources was oriented to other better-quality rocks for knapping tools and the FBO were less used or not at all. However, in the eastern sector of Tandilia, FBO is the most abundant local resource and there was evidence that they were used with varying intensity at the archaeological sites. This research provides data on the use of lithic resources in the humid Pampas subregion and focuses on the development of the expeditive technological procurement and use behavior in the case of FBO rocks.

Keywords: Pampas Region, Tandilia, late Pleistocene-early Holocene, Hunters-gatherers, lithic technology.

\section{Introducción}

En las dos últimas décadas, la información arqueológica generada sobre el poblamiento humano de la región pampeana se incrementó considerablemente y se identificaron, hasta la actualidad, alrededor de 30 sitios arqueológicos en la provincia de Buenos Aires con cronologías correspondientes al Pleistoceno final y al Holoceno temprano. Particularmente en la porción central y oriental de las sierras de Tandilia, se halló la mayor concentración de sitios con ocupaciones tempranas emplazados en aleros, abrigos, cuevas y en menor número, a cielo abierto en el piedemonte y en cimas serranas.

El conocimiento alcanzado sobre este período permitió situar el inicio de la ocupación humana en unos ca. 14.500 años cal. AP (Politis et al. 2016) y discutir aspectos muy variados de los modos de vida de estas sociedades de cazadores-recolectores. Entre los temas que se investigan se destacan los estudios sobre los patrones de ocupación del espacio, la organización tecnológica lítica, las estrategias de subsistencia, las prácticas funerarias y los cambios paleoambientales ocurridos en esos milenios del postglacial (Bayón y Flegenheimer 2004; Bonnat 2018, 2019, 2020a, 2020b; Brea et al. 2020; Flegenheimer 2004; Martínez 2006; Martínez et al. 2015a; Martínez y Mazzanti 2017; Mazzanti 2003; Mazzanti y Bonnat 2013; Mazzanti et al. 2012, 2013, 2019; Mazzia 2010; Politis et al. 2014, 2016, 2019; Rafuse y Massigoge 2020; entre otros).

En estas investigaciones, el estudio de la tecnología lítica ha sido fundamental para reconstruir la historia de estas sociedades, ya que estos artefactos son los elementos que más se conservan en los contextos arqueológicos y permiten discutir distintos aspectos socio-económicos de las poblaciones humanas. En este sentido, se destacan los aportes al conocimiento de las diferentes estrategias, planes y decisiones tecnológicas involucradas en la gestión de los recursos líticos (Armentano et al. 2007; Bayón et al. 1995, 2006; Bonnat 
2020a; Colombo 2011; Flegenheimer et al. 1995, 2015; entre otros). Se propuso que los grupos humanos utilizaron diversas rocas, destacándose las ortocuarcitas de grano fino de Grupo Sierras Bayas (OGSB) y las ortocuarcitas de grano medio y grueso de la Formación Balcarce (OFB), todas procedentes del sistema de Tandilia.

Las ortocuarcitas son rocas sedimentarias formadas casi exclusivamente por granos de cuarzo de tamaño arena unidos por cemento de sílice. Las OGSB pueden contener vetas o lentes con fuerte cementación silícea, granos medios a finos, brillo vítreo y una mayor presencia de rocas blancas. En tanto, las OFB presentan una menor cementación de los granos de cuarzo, los que son de tamaños medianos a grandes y al fracturarse la roca durante la talla, la superficie es rugosa y opaca en relación con las OGSB. Además, esta variedad presenta un mineral oscuro (turmalina) incluido entre los granos de cuarzo (Bayón et al. 1999). Particularmente para las OGSB, se discutió su disponibilidad en el paisaje, la identificación de canteras, su calidad para la talla y la selección de colores para la manufactura de instrumentos (Colombo y Flegenheimer 2013; Flegenheimer y Bayón 1999).

En este marco de investigaciones regionales, el presente trabajo se centró en dilucidar el rol que tuvo Cueva Burucuyá, cuya cavidad fue utilizada como un paradero logístico durante la movilidad de grupos pequeños de cazadores-recolectores, que se hallaban poblando tempranamente el valle serrano del Arroyo La Vigilancia (Bonnat 2020a; Mazzanti y Bonnat 2013). Para ello, se propuso como objetivo caracterizar la implementación del comportamiento tecnológico expeditivo en la talla y uso de las OFB.

En consecuencia, los resultados alcanzados amplían los conocimientos sobre el empleo de recursos líticos en la subregión Pampa húmeda y ponen en valor la importancia del abastecimiento local de las ortocuarcitas de la Formación Balcarce (OFB), destinadas a la talla de instrumentos. Esta roca local de acceso inmediato se halla subrepresentada en los conjuntos líticos de la región bonaerense; en cambio, en este sector del borde oriental de Tandilia resultó un tipo de roca muy utilizada en la talla lítica en sus diversas calidades.

\section{Características generales de la arqueología microregional}

El sector oriental de Tandilia presenta evidencias excepcionales que nutren las investigaciones sobre el poblamiento inicial de la región, como también de los períodos posteriores que dan cuenta de la extensa historia indígena local que continuó hasta las jefaturas ecuestres de finales del siglo XVIII (Mazzanti 2007). Esta área se distingue por su cordón de sierras aisladas y abiertas a las llanuras pampeanas donde se concentran numerosos recursos hídricos (arroyos, manantiales y lagunas). Este borde serrano finaliza en la franja de playas y 
acantilados del litoral marítimo, integrando a los diversos ecosistemas en un radio de ca. $50 \mathrm{~km}$, convirtiéndose en un enclave de biodiversidad excepcional para la vida humana. Estos factores pudieron tener un rol central en las decisiones sociales y económicas de los grupos cazadoresrecolectores que poblaron este sector del paisaje hace unos ca. 12.700 años cal. AP (Mazzanti y Bonnat 2013).

En la microrregión en estudio se descubrieron once contextos arqueológicos en reparos rocosos (Figura 1), datados en el rango cronológico de la transición Pleistoceno-Holoceno (Bonnat y Mazzanti 2015; Bonnat et al. 2015; Mazzanti 1997, 1999, 2003, 2007; Mazzanti et al. 2012, 2013). Las evidencias humanas más antiguas de estos sitios se encuentran en las capas basales de sus secuencias estratigráficas, las que poseen buenas condiciones de integridad y resolución que permitieron abordar distintas líneas de investigación y formularon varios modelos que explican aspectos de los modos de vida de los grupos de cazadores-recolectores. En este sentido, un modelo basado en la arqueología del paisaje (Mazzanti y Bonnat 2013) propuso que las cuevas y aleros integraban una red de lugares dispuestos en cuencas de ocupación (valles y lagunas) con dominio visual y en cerritos de la llanura, señalando la importancia de las geografías de ocupación y de los desplazamientos. Los conjuntos faunísticos correspondientes a este período se conservaron únicamente en dos sitios (Cueva Tixi y Cueva El Abra). Las investigaciones zooarqueológicas permitieron proponer un modelo de subsistencia del tipo generalista, basado en la caza y obtención de presas, que incluía fauna extinguida y actual (Quintana y Mazzanti 2001). Los estudios geoarqueológicos y paleoambientales apoyados en distintos proxies (e.g. fitolitos, diatomeas, sedimentos, antracología, etc.) permitieron reconstruir aspectos climáticos y ambientales del pasado (Brea et al. 2014, 2020; Colobig et al. 2016; Martínez y Mazzanti 2017; Martínez et al. 2013, 2015b).

Particularmente, los conjuntos líticos recuperados en esta microrregión, permitieron abordar el estudio de la organización de la tecnología lítica de esos primeros pobladores, enfatizando en la gestión de las diferentes rocas con el fin de reconocer cuales fueron las estrategias tecnológicas y los circuitos de movilidad regional (Bonnat 2019, 2020a). En los sitios arqueológicos definidos como campamentos residenciales (e.g. Cueva El Abra, Abrigo Los Pinos y Cueva Tixi) sus ocupantes realizaron distintas actividades de talla lítica, generando una amplia diversidad de instrumentos formatizados y desechos de los distintos estadios de la cadena de producción. 


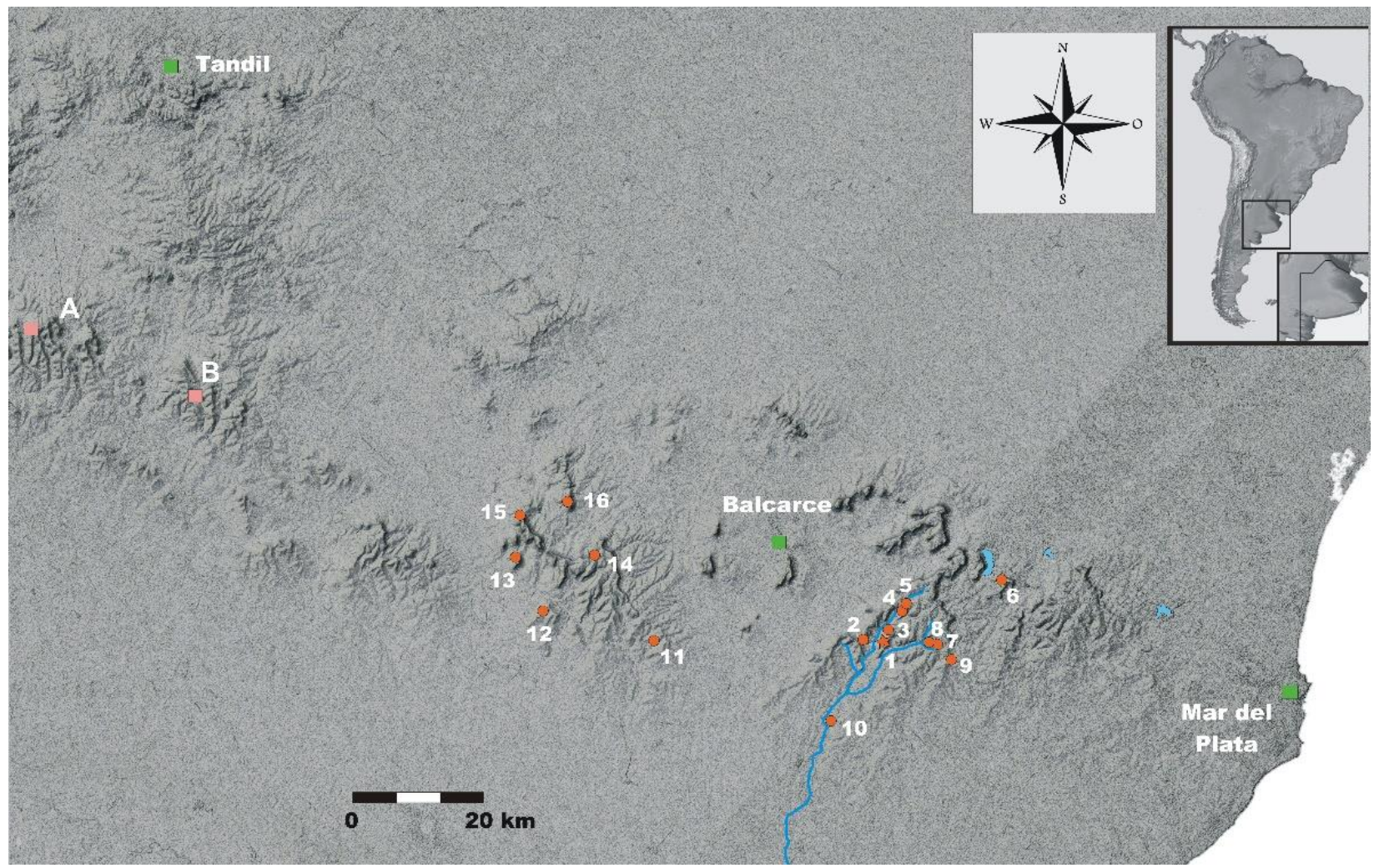

Figura 1. Localización de los sitios tempranos en Tandilia oriental. Referencias: 1) Cueva Burucuyá; 2) Cueva El Abra; 3) Abrigo La Grieta; 4) Abrigo Los Pinos; 5) Alero El Mirador; 6) Cueva La Brava; 7) Cueva Tixi; 8) Cueva Alí Mustafá; 9) Alero Molina I; 10) Localidad Arqueológica Amalia, Sitio 2; 11) Localidad Arqueológica Lobería I, Sitio1; 12) Cerro La China Sitios 1, 2 y 3; 13) Los Helechos; 14) El Aljarafe; 15) Cueva Zoro; 16) Cerro El Sombrero sitios Cima y Abrigo; A) Cantera de OGSB de Barker y B) Canteras de OGSB de La Numancia.

En tanto, en otros reparos caracterizados como de uso efímero para actividades logísticas (e.g. Cueva Burucuyá, Cueva La Brava, Abrigo La Grieta, Alero El Mirador, Cueva Alí Mustafá, Alero Molina I, Lobería I, Sitio 1 y Amalia, Sitio 2), los conjuntos líticos contienen menor cantidad y diversidad de las categorías artefactuales en los estadios de las secuencias de producción. Estos indicadores permiten proponer que esos reparos rocosos fueron estaciones logísticas en los circuitos de movilidad local, utilizados para estadías de corta duración. Posiblemente, fueron sitios elegidos por las partidas de caza/recolección con fines específicos durante los recorridos por las cuencas y llanuras (Mazzanti 2003; Mazzanti y Bonnat 2013). En este escenario microregional, el estudio del conjunto lítico de Cueva Burucuyá adquiere importancia significativa, ya que permitió analizar la gestión de los recursos líticos locales (e.g. OFB), aportando nuevos datos sobre la selección de estas rocas de menor calidad para la talla durante el postglacial. 


\section{La ocupación humana en Cueva Burucuyá}

Este sitio se localiza en la parte media de la margen izquierda del valle de La Vigilancia (Partido de Balcarce) (Figura 1). La cueva resultó un hábitat con características óptimas porque su cavidad es profunda (17 $\mathrm{m}$ de largo), conserva un piso amplio $\left(90 \mathrm{~m}^{2}\right)$ con techo alto en la mayor parte del recinto y una entrada grande (Figuras 2 y 3). La visualización de su abertura facilitó su descubrimiento en 1991. Los sondeos iniciales se realizaron en los años 1993-1994; una vez definida su secuencia estratigráfica (Martínez et al. 1999) con presencia de artefactos líticos hacia la base, se efectuaron las excavaciones arqueológicas obteniéndose la primera datación de la ocupación humana (Mazzanti 1999).

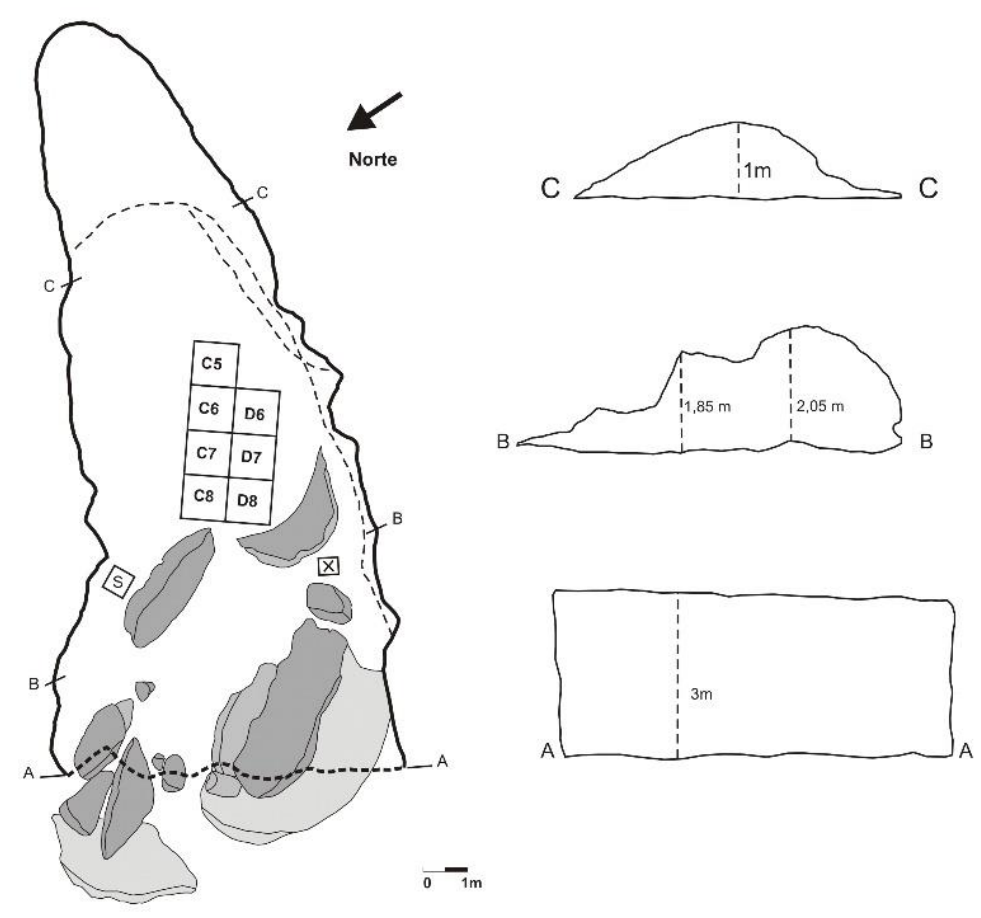

Figura 2. Plano de planta de Cueva Burucuyá con indicación del área de excavación y de tres cortes transversales: A. Boca de forma rectangular, B. Altura máxima en el interior de la cámara, C. Sector posterior donde se originan filtraciones hídricas.

La excavación se efectuó mediante la técnica de extracción de decapados delgados con registros minuciosos de cambios estratigráficos, presencia de rasgos, artefactos y de todas las evidencias de modificaciones naturales y antrópicas. La matriz excavada posee $55 \mathrm{a} 66 \mathrm{~cm}$ de profundidad, formada por cuatro unidades estratigráficas con características singulares. Esta secuencia condensada permitió distinguir claramente la discordancia estratigráfica producida por los cambios paleoclimáticos de la transición Pleistoceno-Holoceno y exponer un fenómeno 
de conservación excepcional de icnitas fósiles. Estas formaron rasgos verticales que variaban de 10 a $25 \mathrm{~cm}$ de diámetro y 15 a $17 \mathrm{~cm}$ de profundidad, ubicadas en el techo de la Unidad 4 (Pleistoceno) (Figura 3d). Las que se interpretaron como improntas de las pisadas producidas por mamíferos grandes sobre sedimentos saturados (Quintana et al. 2001). Este evento resultó un indicador de aspectos paleoclimáticos del postglacial, caracterizado por ciclos de mayor pluviosidad respecto de las condiciones de mayor aridez que predominaron hasta ese período transicional (Martínez y Mazzanti 2017). Todo indica que el ingreso humano a la cueva ocurrió durante las fases climáticas de mayor humedad regional, por ello el contexto arqueológico se sitúa claramente al inicio del depósito sedimentario oscuro (Unidad 3) (Figura 3c y 3d).
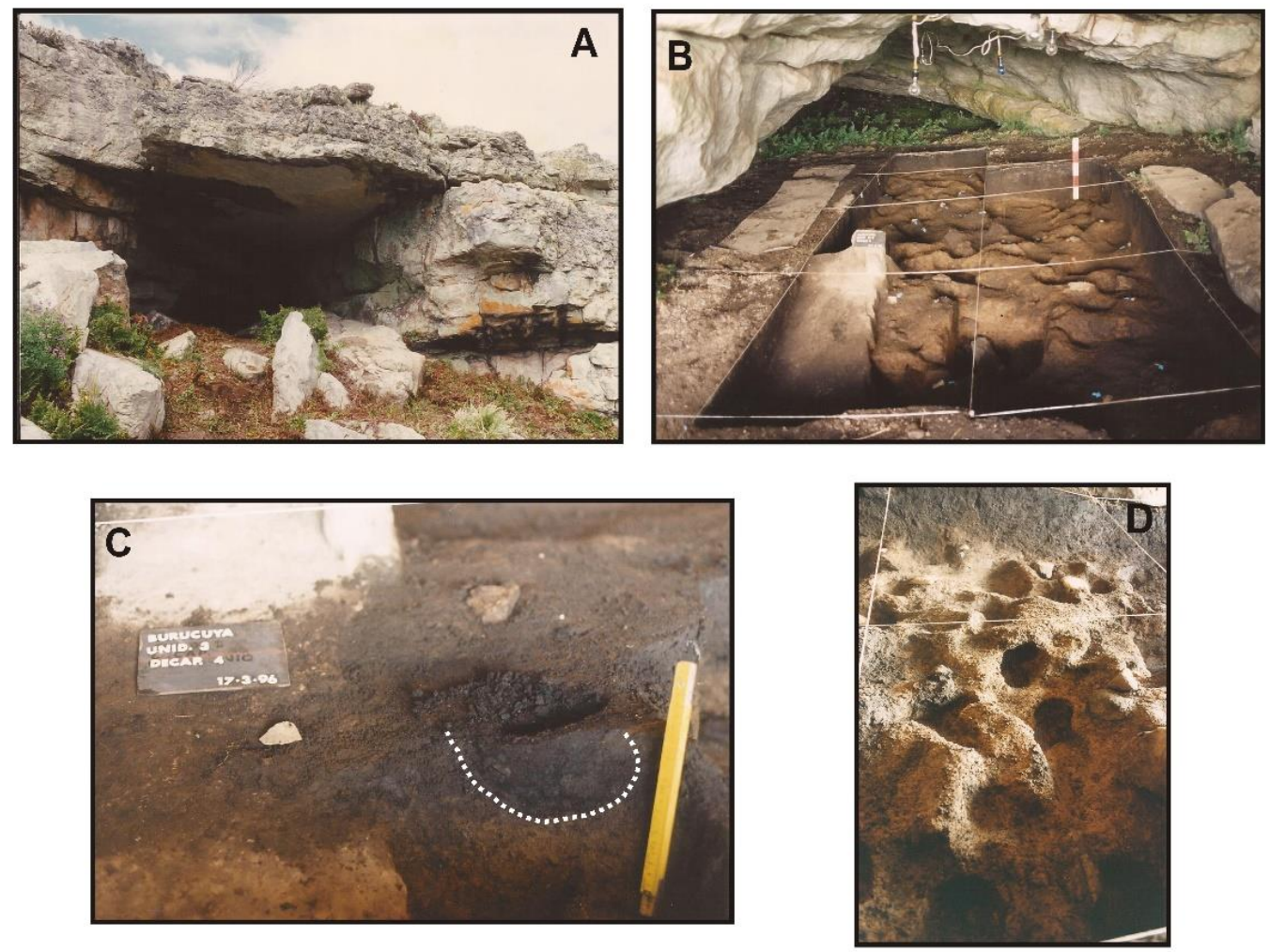

Figura 3. Sitio arqueológico Cueva Burucuyá: A) vista del ingreso a la cueva; B) excavación en área con materiales arqueológicos en los remanentes de la Unidad 3 que apoyaba sobre los rasgos de ignitas;

C) fogón en cubeta en la Unidad 3; D) icnitas sobre los sedimentos amarillentos (Unidad 4).

En la base de la Unidad 3 se identificaron seis fogones formando cubetas de 15 a $22 \mathrm{~cm}$ aproximados de diámetro; cuatro de ellos se hallaron en el sector con mayor luminosidad, presentaban buena conservación y abundantes carbones en sus rellenos (Figura 3c); las muestras fechadas provienen de dos de ellos. Una primera datación fue procesada en 1996 mediante la técnica convencional en el Laboratorio de Tritio y Radiocarbono (LATYR) de la Universidad Nacional de La Plata. Una segunda muestra fue datada en 2011 utilizando la 
técnica de AMS en la Universidad de Arizona (USA) (Tabla 1). Las diferencias cronológicas observadas se deben a los distintos métodos aplicados en el procesamiento de ambas muestras.

\begin{tabular}{|l|c|c|c|c|c|}
\hline \multicolumn{1}{|c|}{ Código } & Años ${ }^{14}$ C AP & Material & $\begin{array}{c}\text { Años cal. AP } \\
\text { (mediana) }\end{array}$ & $\begin{array}{c}\text { Rangos de años } \\
\text { cal. AP (1 sigma) }\end{array}$ & $\begin{array}{c}\text { Rangos de años } \\
\text { cal. AP (2 sigma) }\end{array}$ \\
\hline LP-863 & $10.000 \pm 120$ & Carbón & 11.484 & $11.247-11.524$ & $11.189-11.845$ \\
\hline AA-94640 & $10.672 \pm 56$ & Carbón & 12.655 & $12.618-12.705$ & $12.606-12.733$ \\
\hline
\end{tabular}

Tabla 1: dataciones radiocarbónicas del sitio Cueva Burucuyá. Se utilizó el programa Calib REV 8.2 (Stuiver et al. 2020) y la curva de SHCal 20 (Hogg et al. 2020).

La buena integridad del contexto arqueológico contribuyó a la conservación de fragmentos de carbón que permitieron realizar análisis antracológicos. Las especies identificadas son típicas del bosque xerófito: Celtis tala (tala), Baccharis sp. (chilca) y Senecio sp. (planta herbácea y arbustiva). Estos resultados revelan la combinación de leñas duras (tala) y blandas (chilca y arbusto) con distintos valores energéticos que fueron seleccionadas para el proceso de encendido y mantenimiento calórico de los fogones (Brea et al. 2014, 2020).

\section{Aspectos teóricos y metodológicos}

El estudio de la gestión de la tecnología lítica se centró en la reconstrucción de las cadenas operativas (Karlin 1991; Leroi-Gourhan 1964) en cada tipo de roca. La comprensión de los esquemas conceptuales y operativos permite entender el encadenamiento de actos y gestos técnicos propios de la talla lítica con fines determinados. El análisis de estos procesos implicó la determinación de fuentes de abastecimiento, los métodos, las técnicas y las decisiones aplicadas por el tallador en el uso de los artefactos y el descarte final. Estas etapas se interpretan como un continuum técnico que da cuenta de los esquemas operativos de la talla y de la organización de la producción lítica desarrollada en grandes espacios económicos-sociales (Pellegrin et al. 1988; Perlès 1991; Pigeot 2003; entre otros).

Un aspecto central en el estudio de la gestión de los recursos líticos es la identificación de los tipos de rocas y su ubicación geográfica (Andrefsky 2009; Ericson 1984; entre otros). Esto permite discutir la disponibilidad de los recursos, las distancias de los sitios arqueológicos, las fuentes de abastecimiento, las posibles decisiones y las estrategias que desplegaron los grupos humanos en su obtención (Bamforth 1986; Binford 1979). En este sentido, para ponderar los itinerarios y recorridos geográficos hacia las fuentes de aprovisionamiento, se realizaron algunas modificaciones a los criterios propuestos para la subregión Pampa húmeda (Bayón y Flegenheimer 2004). Por ello, y con el fin de adecuarlos a las características del paisaje y recursos propios de la microrregión en estudio, se proponen las siguientes categorías espaciales: 
a) Los recursos inmediatamente disponibles son aquellas rocas y minerales ubicados en un radio de $10 \mathrm{~km}$ de los sitios, entre los que se incluyen principalmente $\mathrm{OFB}$, pigmentos minerales y rodados de cuarzo procedentes de la misma formación. Esta escala, que en algunos casos varía entre $5 \mathrm{~km}$ a $10 \mathrm{~km}$ de distancia de los sitios, también ha sido considerada por otros autores como recursos o circuitos cercanos a las locaciones arqueológicas (e.g. Berón 2006; Civalero y Franco 2003; Franco 2004; Geneste 1988; Meltzer 1989).

b) Los recursos locales son aquellas rocas y minerales que se disponen en un radio de $50 \mathrm{~km}$ de distancia (sensu Bayón y Flegenheimer 2004), en este caso del sitio Cueva Burucuyá. Esta escala incluye fuentes de aprovisionamiento de la OFB, cuarzo y pigmentos minerales de las sierras y rodados costeros de sílices y basalto en el litoral Atlántico.

c) Los recursos regionales (considerados como distancia media ente 50 y 100 km por Bayón y Flegenheimer 2004), en este trabajo se incluyen las rocas y otros minerales disponibles en un radio entre 50 y $120 \mathrm{~km}$ del sitio, abarcando parte del sector central de las sierras de Tandilia y una mayor superficie de llanuras interserranas y litoral atlántico. Las rocas identificadas son las OGSB ubicadas en la zona de La Numancia, Arroyo Diamante y Barker (Bayón et al. 1999; Colombo 2011; Colombo y Flegenheimer 2013; Flegenheimer et al. 1996, 1999). También se incluyen las dolomías, sílices, andesitas, los diques de diabasa (Teruggi et al. 1974; Vecchi 2016) y canteras de pigmentos minerales de Tandilia central, los rodados de rocas silíceas y basálticas del litoral atlántico (Bonomo y Prates 2014).

d) Los recursos de largas distancias (considerados a más de $100 \mathrm{~km}$ de distancia por Bayón y Flegenheimer 2004) son aquellas rocas y minerales que se ubican a más de $120 \mathrm{~km}$ del sitio Cueva Burucuyá. Se trata de fuentes de abastecimiento de calizas silicificadas (o silcretas) distantes unos $500 \mathrm{~km}$ del sitio, localizadas en la provincia de Entre Ríos y en el actual territorio de Uruguay (Batalla 2016; Bonomo y Blasi 2010; Flegenheimer et. al. 2003; Loponte et al. 2010; Nami 2017). Otras rocas como las riolítas, metacuarcitas y cuarcitas proceden del sistema serrano de Ventania (Catella et al. 2010, 2020; Oliva y Moirano 1997) distante $350 \mathrm{~km}$ de Tandilia.

La metodología de análisis se organizó en varias etapas. En la primera se clasificaron las piezas en dos clases artefactuales (desechos de talla y artefactos formatizados), analizados según los lineamientos de diversos autores (Aschero 1975, 1983; Aschero y Hocsman 2004; Inizan et al. 1995). En una segunda etapa, se identificaron las variables métricas como el tamaño de los artefactos y su relación con módulos (longitud-anchura y anchura-espesor); asimismo, se determinaron grupos tipológicos en los instrumentos, determinando la forma base de los soportes, la situación y extensión de los lascados, la cantidad de filos, sus ángulos, extensión y la presencia de potenciales filos naturales con rastros complementarios (FNRC) reconocidos mediante lupa binocular. Los tipos de rocas 
fueron determinados con la supervisión del geólogo Dr. Gustavo Martínez (LARBO y IGCC-UNMDP), utilizando escalas macro y microscópica (lupa binocular y comparaciones con cortes delgados). En tanto, para identificar las tonalidades de colores se utilizó la propuesta de Munsell (1994) de sedimentos.

Los desechos talla se examinaron aplicando el análisis de número mínimo de desechos (NMD) (Aschero et al. (1993-1994) computando lascas enteras (LENT) y fracturadas con talón (LFCT). El total de los desechos fue tomado para relevar el estado de fragmentación del conjunto y para calcular la frecuencia de materias primas. De esta manera, la inclusión de los desechos fracturados sin talón (LFST) e indiferenciados (INDI) se realizó para evitar sesgos durante el relevamiento de los tipos de rocas, ya que algunas materias primas solo pueden estar representadas en estas dos últimas categorías analíticas y quedan fuera del análisis al utilizar posteriormente la propuesta de número mínimo de desechos.

\section{Resultados del análisis tecnológico}

El conjunto lítico está integrado por 104 artefactos, mostrando una densidad de 14,85 elementos por $\mathrm{m}^{2}$. Se identificaron dos clases artefactuales constituidas por 89 desechos de talla $(85,58 \%)$ y 15 artefactos formatizados (14,42\%). La selección y abastecimiento de las materias primas líticas estuvieron centrados en cuatro variedades de rocas, destacándose las OFB (82,69 \%), seguidas por las OGSB $(14,42 \%)$, calizas silicificadas $(1,92 \%)$ y riolíta $(0,96 \%)$. Se observa que las rocas locales, disponibles en las inmediaciones de la cueva, fueron las más empleadas para la talla.

En las OGSB $(\mathrm{N}=16)$ predominan las variedades de color blanco $(68,75 \%)$ y en menores porcentajes el color gris (12,5 \%), el rojo (12,5 \%) y el marrón rojizo (6,25 \%). No obstante, al separar el conjunto por clases artefactuales se observa que el color blanco domina tanto en los desechos de talla $(77,77 \%)$ como en los artefactos formatizados $(57,14 \%)$, aunque en estos últimos se aprecia una mayor variabilidad de colores, entre los que se incluyen los grises $(28,57 \%)$ y rojizos $(14,28 \%)$. Estas últimas dos tonalidades podrían estar indicando que ingresaron al sitio como instrumentos terminados, ya que no se registraron artefactos producto de otras etapas de la cadena operativa.

\section{Desechos de la talla}

Se identificó un total de 89 desechos en OFB (86,52 \%), OGSB (10,11 \%), caliza silicificada (2,25 \%) y riolíta $(1,12 \%)$. El estado de fragmentación indica un alto índice de lascas fracturadas con talón $(42,7 \%)$, seguidas por las enteras $(28,9 \%)$, las fracturadas sin talón $(23,6 \%)$ y los desechos indiferenciados $(5,62 \%)$. 
En los desechos de talla de ortocuarcitas con talón (NMD $=61$ ) predominan los de tamaños pequeños. En el caso de las OGSB, hay una preeminencia de los medianos pequeños (62,5\%), en tanto que los grandes y muy grandes pertenecen casi exclusivamente a las OFB. Los módulos de longitudanchura para las dos variedades de ortocuarcitas muestran una tendencia hacia el parámetro ancho y mediano alargado en las OGSB, en tanto que las OFB evidencian una mayor diversidad de módulos. En la relación anchura-espesor de las lascas se observa una tendencia hacia los desechos espesos (49,18 $\%$ ). No obstante, en las OGSB hay una leve preferencia hacia los parámetros espesos y poco espesos, en tanto que en las OFB los espesos y los muy espesos están más representados (Tabla 2). Estas evidencias en los tamaños y módulos de las piezas indicarían que, especialmente para las OFB, hay una obtención de lascas con módulos medianos y anchos y de las formas espesas y muy espesas.

En el conjunto lítico predominan los desechos internos, con una amplia diversidad de tipos que están relacionados con las materias primas y las decisiones tecnológicas aplicadas para cada una de ellas. En las OFB se destacan los tipos que evidencian todas las etapas de la talla como, por ejemplo, las lascas y talones que conservan restos de corteza, instancias posteriores en la que se evidencia una mayor frecuencia de lascas planas, de arista y talones lisos y estadios avanzados con tipos angulares y talones lisos y facetados (Tabla 2).

Las OGSB presentan una menor frecuencia de lascas, pero una mayor diversidad de formas y de talones: adelgazamiento bifacial, bipolares, de flanco de núcleo y talones lisos, diedros y facetados. Estas son evidencias de los estadios avanzados de la talla y de la implementación de diversas técnicas de talla involucradas en la formatización de instrumentos líticos.

Los tipos de bulbos difusos predominan en las dos variedades de ortocuarcitas (55,74 \%), seguidos por los no diferenciados $(34,43 \%) \mathrm{y}$, en menor medida, por los pronunciados $(9,84 \%)$. La presencia de desechos con curvatura es baja $(24,59 \%)$ y las evidencias de labio son abundantes $(40,98 \%)$ y más frecuentes en las lascas de OGSB (57,14 \%). Estos indicadores sugieren una técnica de talla relacionada a la percusión directa con percutor blando (Nami 1991; Pigeot 2003; Tixier et al. 1980). La presencia de la preparación de las plataformas de percusión se registró exclusivamente en OGSB y en muy bajos porcentajes $(1,64 \%)$ en correspondencia al abradido.

En este conjunto se identificaron dos lascas de caliza silicificada de tamaño pequeño (blanca y rosa), una de ellas está entera y es angular con talón filiforme, mientras que la restante está fracturada y no posee talón. Estas lascas pertenecen a una variedad de roca con procedencia de larga distancia, indicando actividades puntuales de reactivación de los filos de instrumentos transportados y luego conservados. Asimismo, la identificación de una lasca secundaria de riolita de color rojizo, de tamaño grande con talón liso, es otro dato importante porque esta variedad de roca está vinculada a fuentes de abastecimiento dentro del sistema serrano de Ventania. 


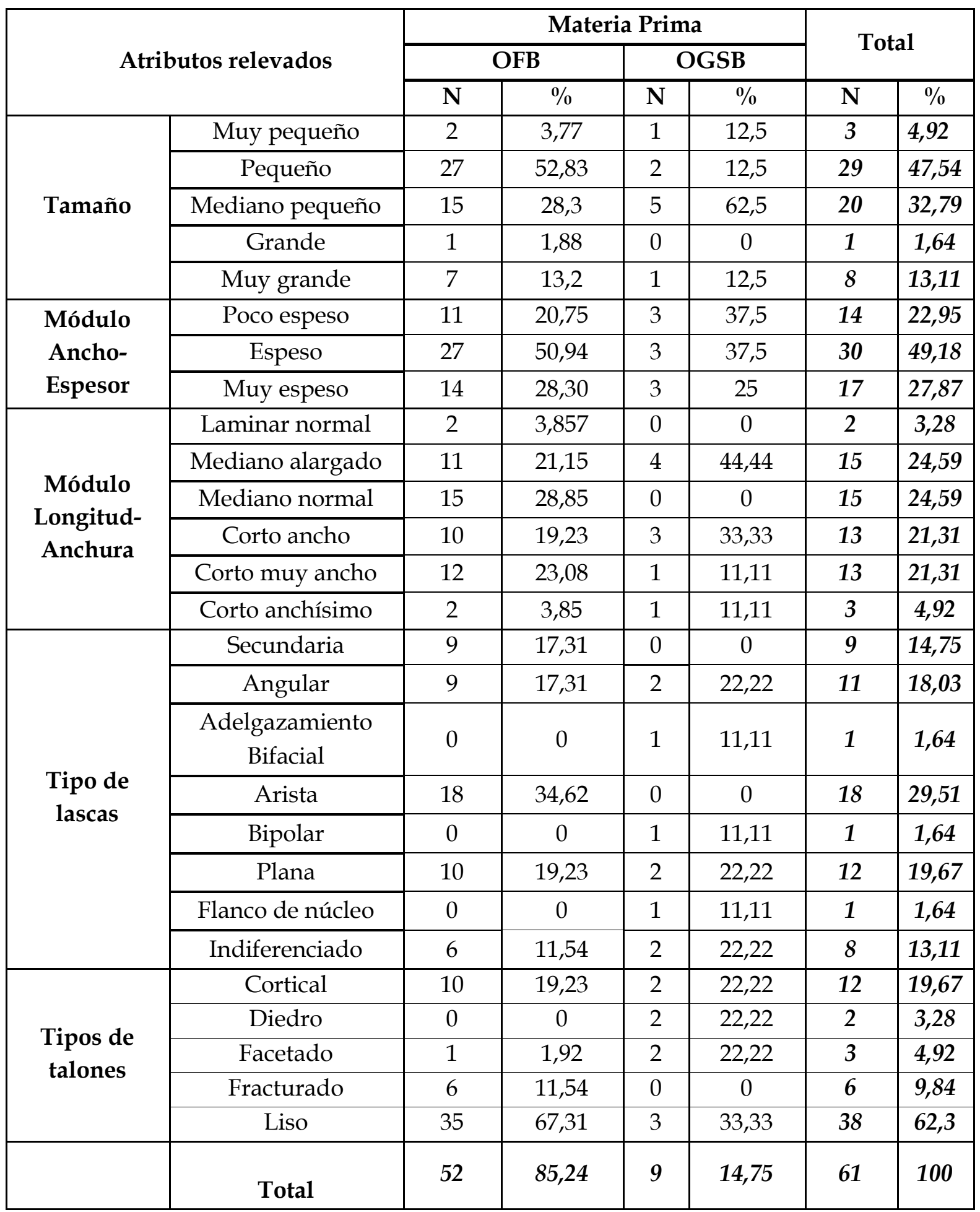

Tabla 2: Desechos de la talla. Principales atributos relevados en las ortocuarcitas. Referencias: OFB.: ortocuarcitas de la Formación Balcarce; OGSB: ortocuarcitas del Grupo Sierras Bayas. 
Instrumentos y filos naturales con rastros complementarios (FNRC)

Se identificaron 15 instrumentos (10 artefactos con filos retocados y cinco FNRC), manufacturados en ortocuarcitas y uno en riolita (Tabla 3). Este conjunto engloba un total de 20 filos asignables a distintos grupos tipológicos, estando 13 retocados y siete presentan rastros complementarios de uso (FNRC).

Las formas base más representadas son las lascas internas $(80 \%)$ y la clase técnica principal (sensu Aschero y Hocsman 2004) es la reducción unifacial (Tabla 3). Las dimensiones de las piezas en OFB señalan una mayor frecuencia de los parámetros grandes (86,66 \%), entre los que se destacan los cepillos (Figura 4$)$, con tamaños muy grande $(n=2)$ y grande $(n=1)$. Además, en el conjunto son claras las diferencias de tamaños de los instrumentos según el tipo de ortocuarcitas y los dos instrumentos tallados en OGSB corresponden al tamaño mediano y en menor frecuencia grandes (Figura 5). Los módulos de longitud-anchura muestran una tendencia hacia las relaciones más anchas que largas en todas las piezas, comprendidas por los módulos corto ancho y corto muy ancho (Tabla 3). Para los módulos de anchura-espesor, se observa una clara tendencia de aquellos espesos, seguidos de los muy espesos (Tabla 3). Los instrumentos de OFB están más representados por los parámetros muy espesos seguidos por los espesos, en tanto que en las OGSB por los espesos $(85,72 \%)$.

En base a estos resultados métricos, independientemente del tipo de ortocuarcita utilizada, no se aprecian diferencias significativas en la relación de los módulos de longitud-anchura. Posiblemente, este patrón responde a una estrategia de talla en la que se seleccionaron módulos cortos y anchos en las dos variedades de rocas, enfatizando los tamaños medianos con módulos espesos en las OGSB y tamaños grandes con módulos muy espesos en las OFB.

La mayoría de los instrumentos presentan filos simples no compuestos y, en menor medida, dobles no compuestos y simple compuesto (Tabla 3). En las OFB los instrumentos con filos simples no compuestos corresponden a cepillos $(n=3)$, FNRC $(n=2)$, raedera $(n=1)$ y una lasca con FNRC de filo doble no compuesto. Por otra parte, en las OGSB los filos simples no compuestos se registraron en raederas $(n=2)$, muesca $(n=1)$ y lasca con FNRC $(n=1)$ y los filos dobles no compuestos se identificaron en los tipos de raedera $(n=1)$, artefacto formatizado no diferenciado $(n=1)$ y lasca con FNRC $(n=1)$. Por último, el instrumento de riolita posee un filo simple compuesto correspondiente a dos grupos tipológicos diferentes (muesca y raspador) (Figura 6).

La extensión de todos los filos ( $\mathrm{N}=20$ ) muestra una considerable diversidad en largos (55 $\%)$, cortos $(15 \%)$, restringidos (10\%), extendidos (10\%) y perimetrales (10\%). Dentro de estos parámetros, los instrumentos de OGSB poseen gran variedad de filos, siendo largos (60\%), 
extendidos $(20 \%)$, cortos y restringidos (10\% respectivamente); por otra parte, en las OFB dominan los filos largos (55,55 \%) y los cortos y perimetrales (22,22 \% respectivamente). El instrumento en riolita posee dos filos restringidos y el interior de la muesca conserva estrías paralelas y transversales, posibles rastros de uso, las que se observaron macroscópicamente y en detalle con lupa binocular (Figura 6b).

\begin{tabular}{|c|c|c|c|c|c|}
\hline \multicolumn{2}{|c|}{ Instrumentos } & \multicolumn{3}{|c|}{ Materias primas } & \multirow{3}{*}{\begin{tabular}{|l|} 
Total \\
$3(20)$
\end{tabular}} \\
\hline & & \multirow{2}{*}{$\begin{array}{c}\text { OFB } \\
\mathbf{N}(\%) \\
3(42,86)\end{array}$} & \multirow{2}{*}{$\begin{array}{c}\text { OGSB } \\
\mathbf{N}(\%) \\
0\end{array}$} & \multirow{2}{*}{$\begin{array}{c}\text { Riolíta } \\
\mathbf{N}(\%)\end{array}$} & \\
\hline Grupos & Cepillo & & & & \\
\hline Tipológicos & FNRC & $3(42,86)$ & $2(28,57)$ & 0 & $5(33,33)$ \\
\hline & $\begin{array}{l}\text { Artefacto formatizado no } \\
\text { diferenciado }\end{array}$ & 0 & $1(14,29)$ & 0 & $1(6,67)$ \\
\hline & Muesca & 0 & $1(14,29)$ & 0 & $1(6,67)$ \\
\hline & I. C. (muesca y raspador) & 0 & 0 & $1(100)$ & $1(6,67)$ \\
\hline & Raedera & $1(14,29)$ & $3(42,86)$ & 0 & $4(26,67)$ \\
\hline \multirow[t]{3}{*}{ Forma base } & Lascas internas & $5(71,42)$ & $6(85,72)$ & $1(100)$ & $12(80)$ \\
\hline & Lascas secundarias & $1(14,28)$ & $1(14,28)$ & 0 & $2(13,33)$ \\
\hline & Nódulo & $1(14,28)$ & 0 & 0 & $1(6,66)$ \\
\hline \multirow[t]{4}{*}{ Tamaño } & Mediano pequeño & 0 & $2(28,57)$ & 0 & $2(13,33)$ \\
\hline & Mediano grande & $1(14,29)$ & $3(42,86)$ & 0 & $4(26,67)$ \\
\hline & Grande & $4(57,14)$ & $2(28,57)$ & $1(100)$ & $7(46,67)$ \\
\hline & Muy grande & $2(28,57)$ & 0 & 0 & $2(13,33)$ \\
\hline \multirow{2}{*}{$\begin{array}{l}\text { Módulo } \\
\text { Ancho- } \\
\text { Espesor }\end{array}$} & Espeso & $3(42,85)$ & $6(85,72)$ & $1(100)$ & $10(66,67)$ \\
\hline & Muy espeso & $4(57,14)$ & $1(14,28)$ & 0 & $5(33,33)$ \\
\hline \multirow{4}{*}{$\begin{array}{l}\text { Módulo } \\
\text { Longitud- } \\
\text { Anchura }\end{array}$} & Mediano alargado & $1(14,28)$ & $1(14,28)$ & 0 & $2(13,33)$ \\
\hline & Mediano normal & $2(28,57)$ & $1(14,28)$ & 0 & $3(20)$ \\
\hline & Corto ancho & $3(42,85)$ & $4(57,14)$ & $1(100)$ & $8(53,33)$ \\
\hline & Corto muy ancho & $1(14,28)$ & $1(14,28)$ & 0 & $2(13,33)$ \\
\hline \multirow[t]{3}{*}{ Filos } & Simples compuestos & 0 & 0 & $1(100)$ & $1(6,67)$ \\
\hline & Simples no compuestos & $6(85,72)$ & $4(57,14)$ & 0 & $10(66,67)$ \\
\hline & Dobles no compuestos & $1(14,28)$ & $3(42,86)$ & 0 & $4(26,67)$ \\
\hline & Total & $7(46,67)$ & $7(46,67)$ & $1(6,66)$ & $15(100)$ \\
\hline
\end{tabular}

Tabla 3: Frecuencias absolutas y relativas de los atributos relevados en instrumentos por materia prima. Referencias: OFB: ortocuarcitas de la Formación Balcarce; OGSB: ortocuarcitas del Grupo Sierras Bayas; FNRC: filos naturales con rastros complementarios; I. C.: instrumento compuesto. 


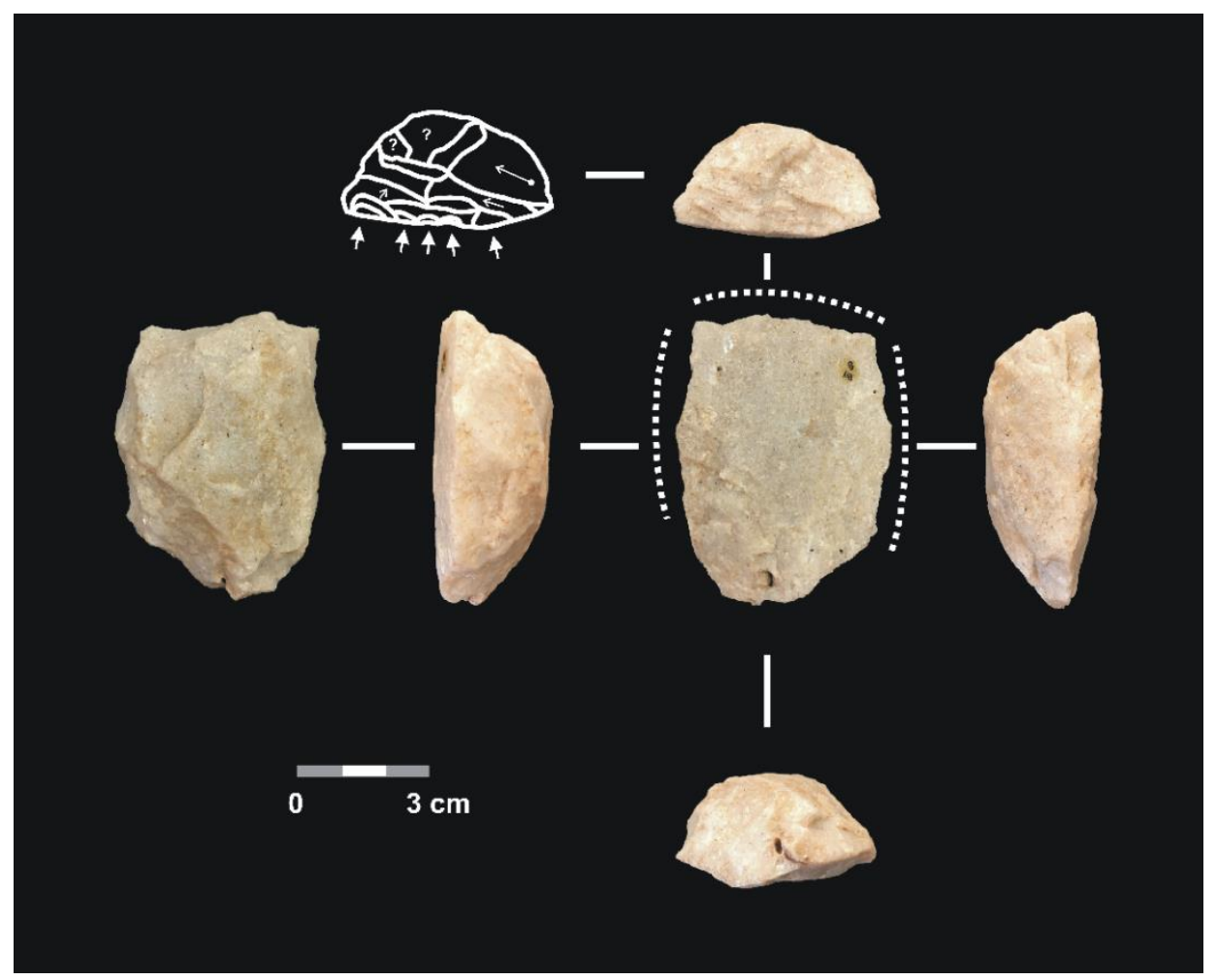

Figura 4. Cepillo de OFB de filo semi-perimetral.

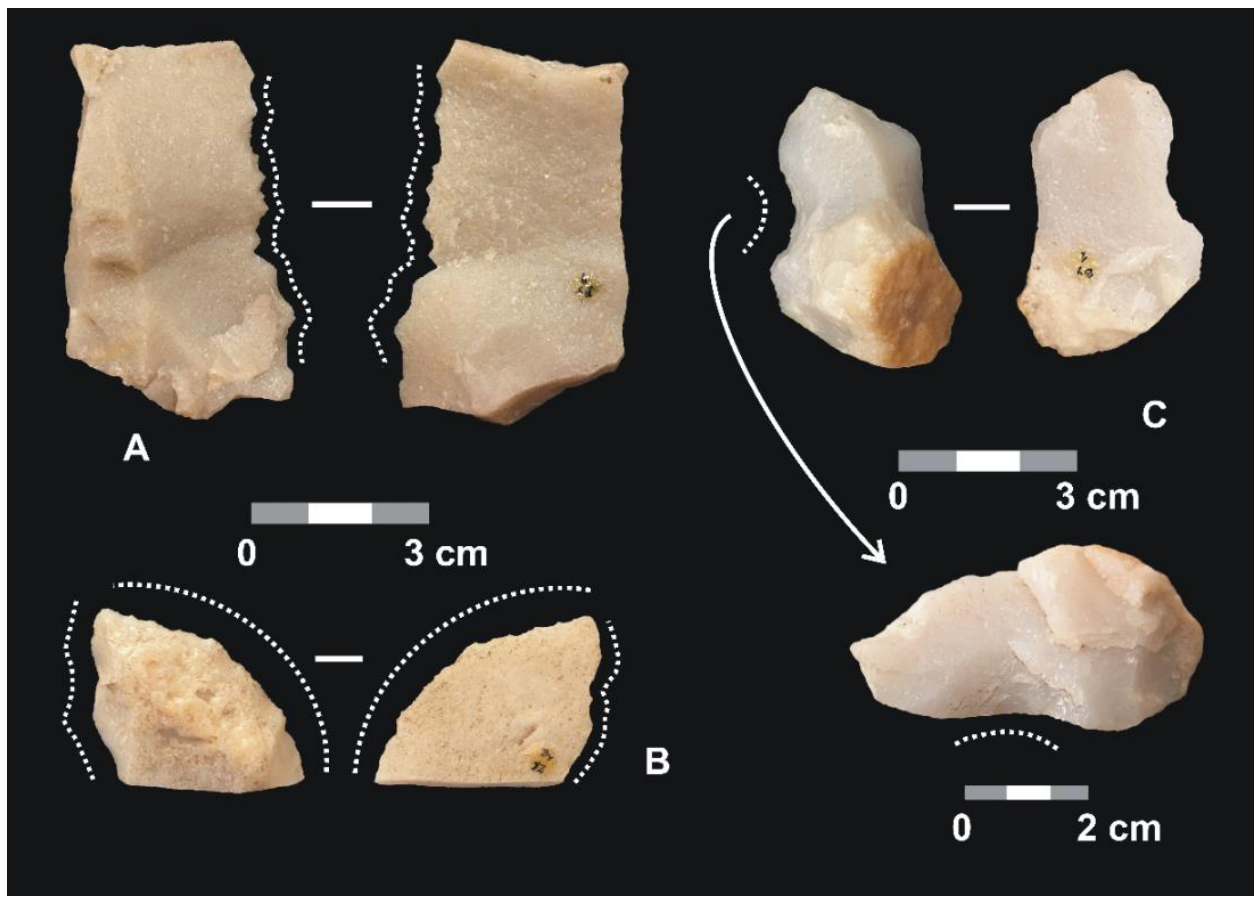

Figura 5. Instrumentos de OGSB. A) raedera de filo lateral denticulado; B) fragmento de raedera de filo convergente en punta, y C: muesca de filo lateral. 


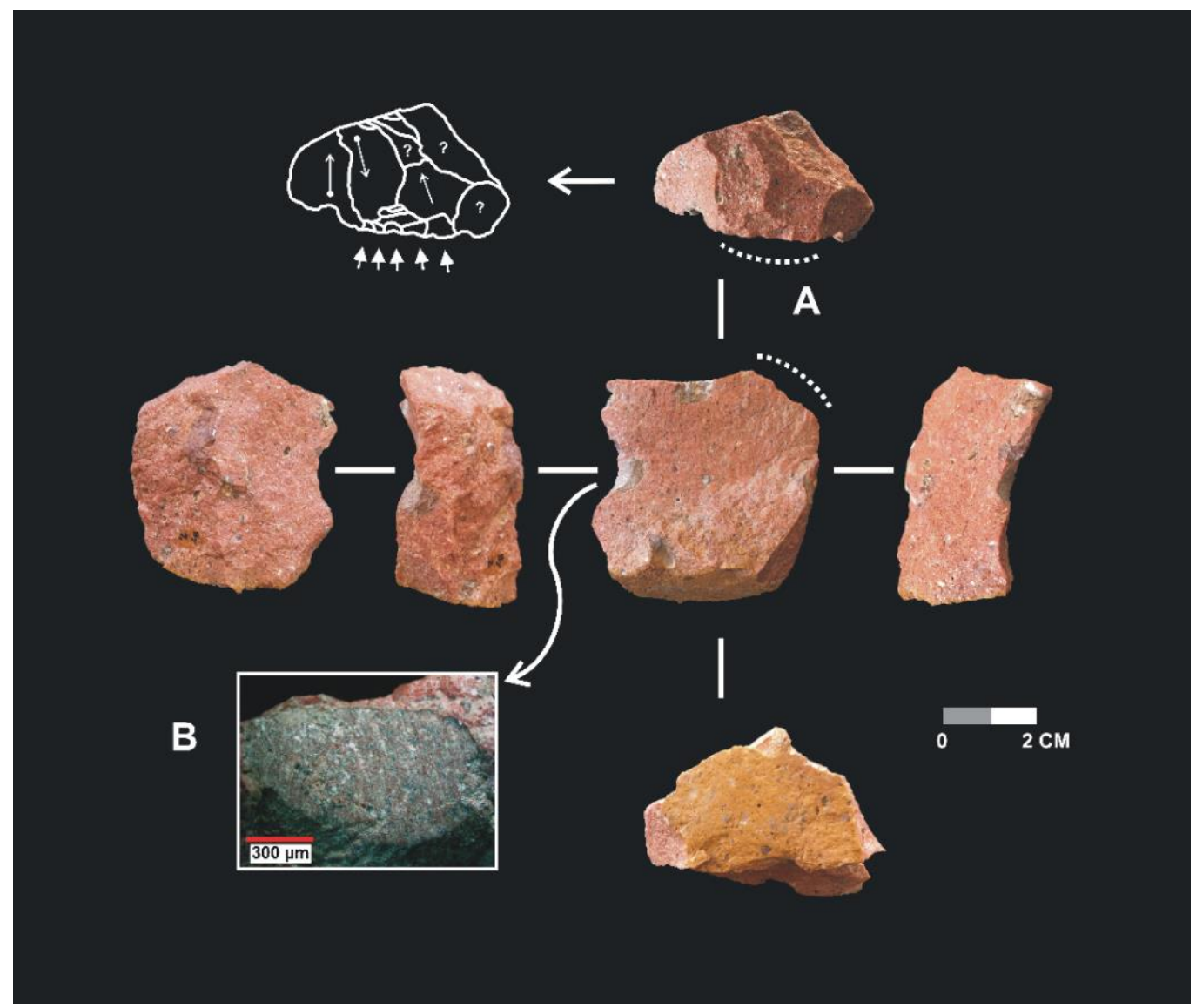

Figura 6. Instrumento compuesto de riolita. A) filo de raspador y B) detalle de la muesca.

La formatización de los filos $(n=13)$ fue realizada principalmente por retoque $(59,53$ $\%)$, seguido por la retalla y la combinación de retalla y retoque $(15,38 \%$ para cada una) y, en menor medida, el lascado simple de formatización $(9,71 \%)$. En el caso de las piezas de OGSB, se utilizó el retoque marginal para la manufactura de dos raederas (una de ellas con filo denticulado irregular), la muesca y el fragmento no diferenciado de artefacto formatizado (Figura 5) y el retoque extendido en la manufactura del filo de una raedera.

Los tres cepillos de OFB poseen los filos formatizados por retalla marginal y la combinación de retoque y retalla parcialmente extendida (Figura 4), en tanto que la raedera presenta retoque marginal. Por último, el instrumento compuesto de riolita posee un lascado simple en la muesca y un retoque marginal en el filo de raspador. Estos aspectos tecnológicos de la serie técnica, posiblemente estén relacionados con la granulometría de las rocas y las decisiones tecnológicas para formatizar instrumentos. 
La situación de los lascados indica reducción unifacial directa en todos los casos $(\mathrm{N}=13)$ y lascados paralelos cortos regulares $(30,77 \%)$, no diferenciados $(23,08 \%)$, paralelo corto irregular y escamoso irregular $(15,38 \%$ respectivamente) $\mathrm{y}$, por último, lascado único y escamoso escalonado (7,6 \% en cada uno). La forma de los filos indica que el 76,92 \% son regulares, el 15,38 $\%$ de tipo sinuosos irregulares y el 7,69 \% sinuosos regulares.

Los FNRC ( $\mathrm{n}=7)$ sobre lascas de OFB representan el $57 \%$, en cambio, los producidos con OGSB alcanzan el $42 \%$. La selección de soportes estuvo orientada exclusivamente a las lascas internas en ambas variedades de ortocuarcitas. Los filos más representados son los dobles (57,14 $\%$ ) y los filos simples se registraron en una $42,86 \%$. Los rastros complementarios comprenden mayoritariamente microastilladuras y lascados aislados $(85,71 \%)$, también se observaron aristas pulidas $(14,29 \%)$.

\section{Discusión}

La abundancia, disponibilidad y predictibilidad de la OFB en el paisaje permitió la implementación de un plan tecnológico basado en la gestión expeditiva (Binford 1979; Nelson 1991) de esa materia prima. La característica particular del proceso de talla registrada en Cueva Burucuyá, muestra la intencionalidad en lograr instrumentos destinados a trabajos específicos durante la ocupación transitoria. Las distintas etapas de las cadenas operativas identificadas son un claro indicador de la producción de instrumentos in situ (Figura 7). El abastecimiento de las OFB se realizó en las inmediaciones, estando disponible en los estratos subhorizontales y bloques de la pendiente serrana y en clastos o rodados que se encuentran a lo largo de la cuenca del Arroyo La Vigilancia, distante un kilómetro. No obstante, su obtención requirió de la selección de aquellos nódulos que contuvieran la variedad de grano medio-fino.

La presencia de lascas secundarias, talones corticales, tamaño grande y muy grande con módulos muy espesos en OFB, evidencian las primeras etapas de la cadena operativa, orientadas al descortezamiento inicial mediante el desbaste de nódulos y/o lascas nodulares de gran tamaño. Luego, los gestos técnicos de la talla se orientaron a la obtención de lascas y formas bases grandes, con intención de obtener soportes anchos, espesos muy espesos y formatizar instrumentos como los cepillos y la raedera (Figura 4). Estos instrumentos presentan fuerte relación de afinidad en cuanto al tamaño, color y granulometría con las variedades de rocas identificadas en los desechos de talla. Los instrumentos en OFB evidencian una baja inversión de tiempo de trabajo en su formatización, son piezas no estandarizadas, sin regularización del bisel, no hay talla bifacial ni acciones de mantenimiento o reciclaje, etc. El bisel de los instrumentos presenta formas de filos simples convexos que fueron formatizados mediante la combinación de retoque y retalla marginal 
unifacial y se delinearon filos de distintas longitudes (largos, cortos y perimetrales). En el caso de los cepillos, posiblemente fueron utilizados en ángulo abrupto en acciones transversales para trabajos sobre maderas, como se ha evidenciados en sitios de la región (Pal et al. 2019; Leipus 2014). La granulometría de la OFB es un factor que pudo potenciar el trabajo sobre maderas de distintas durezas y estados. En base a los estudios antracológicos (Brea et al. 2020) se conocen varias especies vegetales que fueron introducidas a la cueva para fines calóricos, lo que indica cuales fueron las especies arbóreas de maderas duras, blandas y arbustos que se hallaban presente en el valle. Estas maderas estuvieron dispuestas para la confección de instrumentos intermediarios, astiles, mangos, etc.

\section{OFB}

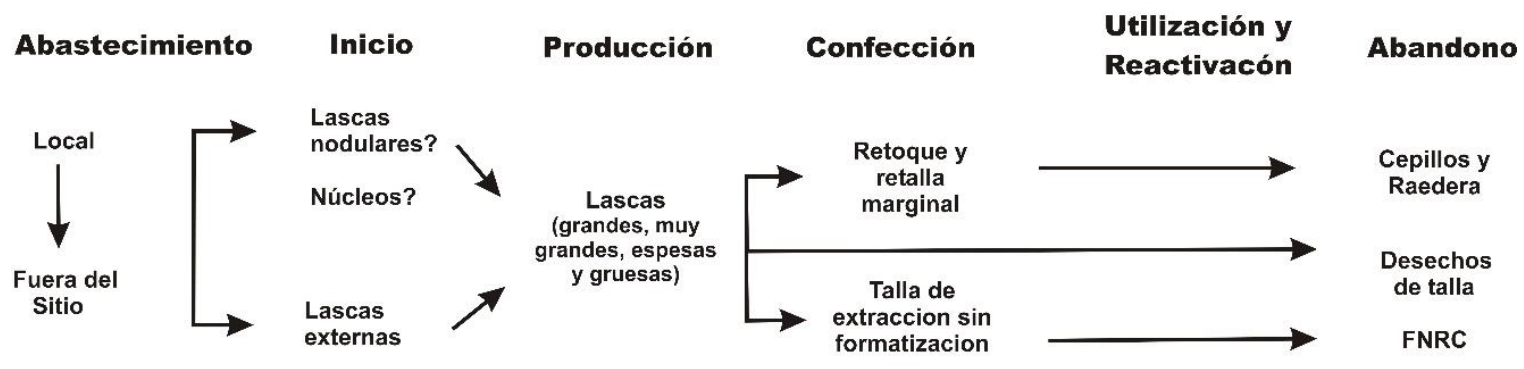

\section{OGSB}

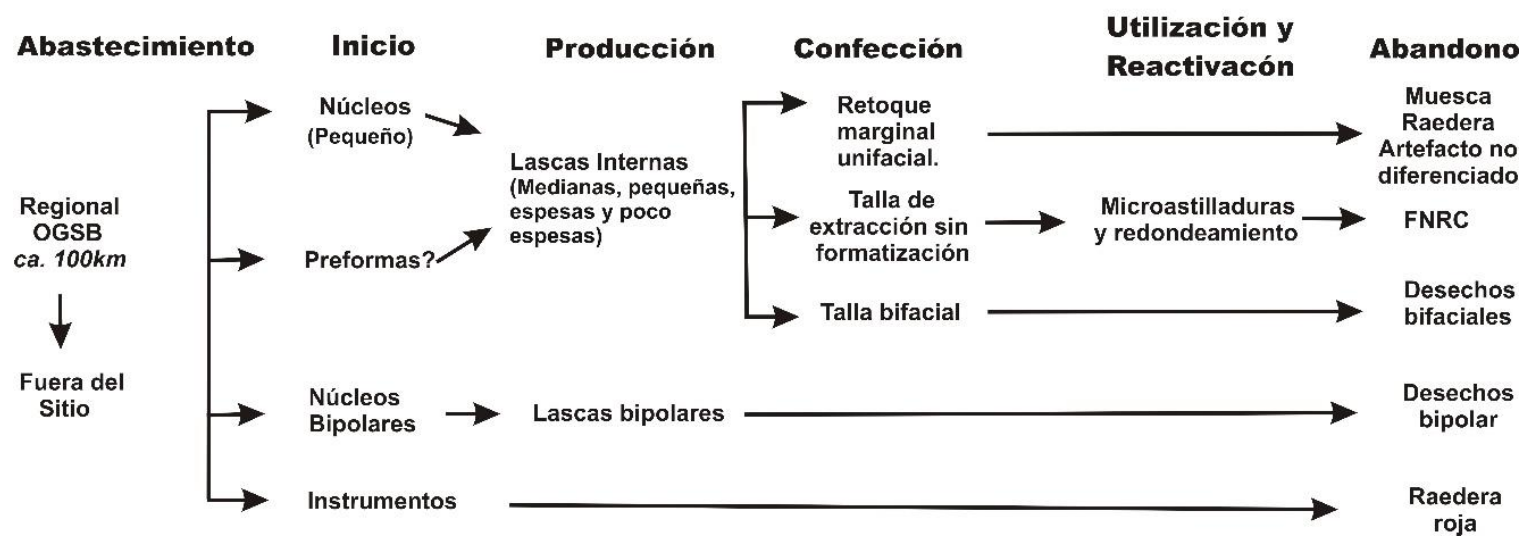

Figura 7. Cadenas operativas de las OFB y OGSB.

En cambio, en las OGSB se observó una gestión distinta a la OFB (Figura 7). Estas rocas evidencian estadios avanzados de la cadena operativa y un mayor despliegue de técnicas de talla en la formatización. El abastecimiento de esta ortocuarcita de grano fino se produjo regionalmente, posiblemente en los complejos de canteras y talleres del Picadero, La Numancia y/o Arroyo Diamante, ubicados en el sector central de Tandilia, ca. 90 a $100 \mathrm{~km}$ del sitio Cueva Burucuyá. Las etapas iniciales de la talla, vinculadas a la preparación y acondicionamiento para 
el transporte de la roca, debieron comenzar en esas canteras, posteriormente ingresaron al sitio como núcleos, preformas y/o instrumentos finalizados. Los indicadores de talla corresponden a lascas internas de diversos tipos (e.g. angulares, planas, de adelgazamiento bifacial, bipolar, tableta de núcleo, etc.) y de dimensiones medianas, pequeñas y muy delgadas, vinculadas, como se expresó, a los estadios avanzadas de la cadena operativa. Al igual que lo observado para las rocas locales (OFB), las evidencias de bulbos difusos, conos poco marcados y labios definidos en un $40 \%$ de las piezas, permitirían pensar en una técnica de talla posiblemente relacionada a la percusión directa con percutor blando (Nami 1991; Pigeot 2003). Los indicadores de talla bipolar y de la reducción y/o adelgazamiento bifacial son escasas en el sitio, por lo que éstas no serían las técnicas de talla preferencial a diferencia de lo registrado en otros sitios tempranos de la región (Bonnat 2019, 2020a; Bonnat y Mazzanti 2015; Flegenheimer 2004; Flegenheimer et al. 2015; Mazzanti et al. 2013).

Los instrumentos producidos con OGSB (e.g. raederas, muesca, instrumentos no diferenciado y FNRC) posiblemente estuvieron destinados a tareas de corte y raspado. En su formatización no se observa estandarización en la regularización de los biseles, ya que fueron realizados principalmente por retoque unifacial marginal $\mathrm{y}$, en menor medida, con retalla unifacial. El retoque profundo se registró en un solo caso. Los FNRC poseen microastilladuras y microlascados. Si bien, resta realizar los estudios funcionales de base microscópica, el análisis tecno-morfológico realizado, sumado a los resultados antracológicos (Brea et al 2019), resultan una buena base para proponer como posible, la utilización de estas piezas para el procesamiento de madera como ya fue registrado en otros sitios de la región (Pal et al. 2019; Leipus 2014).

En base al análisis de estas dos variedades de ortocuarcitas, se observaron algunas semejanzas en la técnica de talla y formatización de los artefactos, siendo, sin embargo, los objetivos de la talla diferentes para cada variedad. Con las OFB se buscó producir soportes grandes y espesos, asociados con la manufactura de instrumentos que cubrieran actividades puntuales y concretas como los cepillos. En cambio, las OGSB conllevan mayor tiempo y esfuerzo del artesano, ya que se evidencia, en bajos porcentajes, un mayor despliegue de técnicas y estrategias de talla: bifacial, bipolar, acondicionamiento de núcleo, preparación de la plataforma de percusión y frente de extracción en la obtención de las lascas, retoque extendido en la configuración de filos, etc.

En cuanto a la roca procedente de larga distancia, la caliza silicificada, fue identificada en dos lascas producto de la reactivación y mantenimiento de dos instrumentos conservados. Estas dos pequeñas piezas posiblemente procedan de los actuales territorios de Entre Ríos (Argentina) o de la República Oriental del Uruguay (Batalla 2020a; Bonomo y Blasi 2010; Flegenheimer et al. 2003; Loponte et al. 2010; Nami 2017). 
Por último, el instrumento de riolita presenta dos tipos de filos (muesca y raspador), cuyos caracteres tecnomorfológicos (tipo de retoque y ángulo) y la granulometría de la roca permiten proponer que fue destinado a tareas vinculadas al raspado. Esta roca de procedencia regional, obtenida posiblemente en las sierras de Ventania $(c a .350 \mathrm{~km}$ ), fue transportada a la cueva como instrumento finalizado o bien como forma base. En el registro lítico se identificó una lasca secundaria, posiblemente desprendida del mismo núcleo.

\begin{tabular}{|c|c|c|}
\hline Área & Sitio arqueológico & OFB \\
\hline \multirow{4}{*}{ Tandilia oriental } & Cueva Burucuyá & $82,69 \%$ \\
\cline { 2 - 3 } & Abrigo Los Pinos & $64,71 \%$ \\
\cline { 2 - 3 } & Localidad Arqueológica Amalia Sitio 2 & $53,33 \%$ \\
\cline { 2 - 3 } & Cueva El Abra & $51,15 \%$ \\
\cline { 2 - 3 } & Cueva Tixi & $43,29 \%$ \\
\cline { 2 - 3 } & Cueva Alí Mustafá & $36,23 \%$ \\
\cline { 2 - 3 } & Alero El Mirador & $33,77 \%$ \\
\cline { 2 - 3 } & Localidad Arqueológica Lobería Sitio 1 & $33,33 \%$ \\
\cline { 2 - 3 } & Abrigo La Grieta & $31,2 \%$ \\
\hline Tandilia centro-oriental & Cueva La Brava & $16,31 \%$ \\
\cline { 2 - 3 } & Cueva Zoro & $33,33 \%$ \\
\cline { 2 - 3 } & El Aljarafe & $25 \%$ \\
\cline { 2 - 3 } & Cerro La China Sitio1 & $18,6 \%$ \\
\cline { 2 - 3 } & Cerro La China Sitio 2 & $11 \%$ \\
\cline { 2 - 3 } & Cerro La China Sitio 3 & $5,8 \%$ \\
\cline { 2 - 3 } & Cerro El Sombrero Abrigo & \\
\cline { 2 - 3 } & &
\end{tabular}

Tabla 4. Ortocuarcitas de la Formación Balcarce identificados en los sitios temprano de Tandilia.

En los sitios de Tandilia oriental asignables a la transición Pleistoceno final y Holoceno temprano, se utilizaron más de quince variedades de rocas para la manufactura de los artefactos (Bonnat 2019). Como se expresó, la OFB de grano medio fue una de las rocas más utilizadas en estos campamentos (Tabla 4); no obstante, la intensidad de su uso varió según fueran las decisiones tecnológicas y sociales tomadas en cada sitio. En la escala regional, las OFB se presentan en bajos porcentajes en la mayoría de los conjuntos líticos tempranos de la provincia de Buenos Aires (Bonnat 2020a). De esta forma, la utilización de las OFB decae en el sector centro-oriental de Tandilia (Tabla 4), a pesar de que esta roca se encuentra en el mismo cordón serrano donde se emplazan los sitios y está disponible localmente (Flegenheimer et al. 2015; Mazzia 2010). No obstante, la gestión de los recursos líticos en esos sitios estuvo orientada a las ortocuarcitas de mejor calidad para la talla (e.g. OGSB). Las canteras arqueológicas se ubican entre ca. 30 a $75 \mathrm{~km}$ de distancia, configurando su proximidad a las fuentes de extracción, el factor que facilitó el flujo de esa materia prima hacia el sistema tecnológico y consecuentemente 
la presencia de todas las fases del sistema de producción. Esta condición de cercanía pudo favorecer el desarrollo de planes, decisiones y estrategias tecnológicas diferentes a las de Tandilia oriental. Por otra parte, en el área Interserrana y en Tandilia occidental, prácticamente no se evidencia el uso de OFB. El abastecimiento de rocas estuvo orientado a otras materias primas (e.g. OGSB, dolomía silicificada, ftanita, etc.) procedentes de distintos lugares del paisaje, tanto en una escala local como regional (Armentano et al. 2007; Bayón y Flegenheimer 2004, Bayón et al. 1999; Colombo 2011; Messineo y Barros 2015; entre otros).

\section{Conclusión}

Cueva Burucuyá fue definida como un asentamiento de uso efímero ocupado por cazadores-recolectores durante la transición Pleistoceno-Holoceno, en momentos cuando se comenzaba a explorar y poblar el sector oriental de las sierras de Tandilia. Posiblemente su función fue de campamento de actividades logísticas dentro de un componente collectors de ocupación del paisaje (sensu Binford 1980), de acuerdo con los resultados previos obtenidos (Bonnat 2020a). Esta cueva, fue un refugio muy apropiado por sus dimensiones, ubicación geográfica y la presencia de agua en su interior (surgente temporaria en la parte posterior). Su cámara amplia brindó un hábitat propicio, al igual que otros reparos vecinos utilizados durante los circuitos de movilidad dentro de los dos valles (cuencas de ocupación) que caracterizan al macizo serrano de La Vigilancia. Sus ocupantes realizaron actividades, creando fogones en forma de cubetas, modalidad que potenció favorablemente el proceso de combustión con fines calóricos/cocción de alimentos. La buena conservación de esas estructuras de combustión podría indicar que la cueva estuvo ocupada por un número reducido de personas durante su corta permanencia.

Para la producción lítica seleccionaron cuatro variedades de rocas, las que fueron transportadas en distintos estadios de la cadena de operativa. Las OFB, de disponibilidad local, fueron las más utilizadas y las características del conjunto lítico revelan su importancia en la producción de artefactos líticos durante la ocupación de la cueva.

En base al análisis tecno-morfológico, se observa que los grupos cazadores-recolectores desarrollaron un componente tecnológico expeditivo (Binford 1979; Nelson 1991) en la utilización de las OFB. Las tareas realizadas en su interior, requirieron de cepillos, raederas y muescas y complementariamente de lascas con filos naturales. Dentro de un comportamiento continuum de las estrategias conservadas y expeditivas desarrolladas por estos grupos de cazadoras-recolectoras tempranos (Bonnat 2020a), la abundancia, diversidad y predictibilidad de las OFB en el paisaje, configuraron un reservorio de materias primas que permitió un abastecimiento fluido y directo de las mismas, aspecto que favoreció la implementación de este plan expeditivo. Los requerimientos funcionales de los instrumentos en OFB se vieron 
cumplidos a través de la talla basada en la obtención de formas bases no estandarizadas y en la escasa regularización de los filos. En cambio, las decisiones y estrategias tecnológicas implementadas para la formatización de las OGSB evidencian un mayor despliegue de gestos y técnicas que posiblemente estén relacionadas con la calidad de esta roca para la talla y con los costos que implican la obtención de las mismas.

Por último, es interesante notar que el mayor uso de los recursos locales (OFB) en Cueva Burucuyá, coincide con uno de los fechados más antiguos (10,672 \pm 56 años AP) para este sector del sistema serrano de Tandilia. En un modelo de poblamiento humano regional no direccionado (sensu Borrero 1994-1995) en el que se esperan distintos indicadores arqueológicos para cada una de las etapas del proceso de poblamiento (sensu Borrero y Franco 1997), se plantea que el grupo de cazadores-recolectores que ocuparon Cueva Burucuyá estarían en una etapa de exploración (Borrero 1994-1995). En este sentido, en el sitio se priorizó el uso de los recursos minerales locales en la manufactura de instrumentos expeditivos (Borrero y Franco 1991; Franco 2004), destinados a la ejecución de trabajos productivos puntuales, en un campamento de uso efímero durante la movilidad por la cuenca de ocupación de la Vigilancia, la que comenzaba a ser poblada.

Agradecimientos: Agradecemos al Consejo Nacional de Investigaciones Científicas y Tecnológicas (CONICET), a la Agencia Nacional de Promoción Científica y Tecnológica por el otorgar los subsidios PICT 2008 ( No 1390), PICT 2013 ( N 1979) y PICT 2017 ( N $^{\mathrm{o}}$ 1027) y a la Universidad Nacional de Mar del Plata por el brindarnos el espacio de trabajo y apoyo económico. Al Dr. Gustavo A. Martínez por su colaboración en la identificación mineralógica de las rocas y a los Dres. Gustavo Martínez y Adolfo Gil por su ayuda con la calibración de los fechados. Agradecemos a los evaluadores cuyos comentarios y sugerencias mejoraron el presenta artículo. También deseamos agradecer a los propietarios del campo, quienes nos brindaron su generosa hospitalidad a lo largo de las varias décadas de trabajo. Todo lo expresado en este artículo es responsabilidad de los autores.

\section{Bibliografía citada}

Andrefsky Jr., W.

2009 The analysis of stone tool procurement, production and maintenance. Journal of Archaeological Research 17:65-103.

Aschero, C.

1975 Ensayo para una clasificación morfológica de artefactos líticos aplicada a los estudios tipológicos comparativos. Informe CONICET. Ms.

1983 Registro de Códigos para atributos descriptivos aplicados a artefactos líticos. Informe CONICET. 
Aschero, C. y S. Hocsman.

2004 Revisando cuestiones tipológicas en torno a la clasificación de artefactos bifaciales. En Registros del Pasado 1 (ed. por M. Ramos, A. Acosta y D. Loponte), pp. 2-25. Universidad Nacional de Luján, Luján.

Aschero, C., L. Manzi y A. Gómez

1993-1994 Producción lítica y uso del espacio en el Nivel 2b4 de Quebrada Seca 3. Relaciones de la Sociedad Argentina de Antropología XIX: 191-214.

Armentano, G., G. Martínez y M. Gutiérrez

2007 Revisión del sitio Paso Otero 5: aspectos tecnológicos y fuentes de aprovisionamiento. En Arqueología en las pampas (ed. por C. Bayón, A. Pupio, M. González, N. Flegenheimer, y M. Frère), Tomo II, pp 535-548. Sociedad Argentina de Antropología, Buenos Aires.

Bamforth, D.

1986 Technological efficiency and tool curation. American Antiquity 51: 38-50.

Batalla, N.

2016 Studies of indigenous lithic procurement in Uruguay and their implications for Southern Cone archaeology. Journal of Lithic Studies 3: 265-292.

Bayón, C. y N. Flegenheimer

2004 Cambio de planes a través del tiempo para el traslado de roca en la Pampa Bonaerense. Estudios Atacameños 28: 59-70.

Bayón, C., P. Escola y N. Flegenheimer

1995 Organización tecnológica: usos y abusos de esta perspectiva. Arqueología 5:179-186.

Bayón, C., N. Flegenheimer, M. Valente y A. Pupio.

1999 Dime cómo eres y te diré de dónde vienes: Procedencia de rocas cuarcíticas en la región pampeana. Relaciones de la Sociedad Argentina de Antropología XXIV: 187-235.

Bayón, C., N. Flegenheimer y A. Pupio.

2006 Planes sociales para el abastecimiento y traslado de roca en la Pampa Bonaerense en el Holoceno temprano y tardío. Relaciones de la Sociedad Argentina de Antropología XXXI: 19-45.

Berón, $\mathrm{M}$.

2006 Base regional de recursos minerales en el occidente pampeano. Procedencia y estrategias de aprovisionamiento. Relaciones de la Sociedad Argentina de Antropología XXXI: 47-88. 
Binford, L.

1979 Organization and Formation Processes: looking at Curated Tecnologies. Journal of Anthropological Research 35: 255-273.

1980 Willow smoke and Dog's tails: hunter-gatherer settlement system and archaeological site formation. American Antiquity 45: 4-20.

Borrero, L.

1994-1995 Arqueología de la Patagonia. Palimpsesto 4: 9-69.

Borrero, L. y N. Franco

1997 Early Patagonian hunter-gatherers: subsistence and technology. Journal of Anthropological Research 53: 219-239.

Bonnat, G.

2018 Análisis del conjunto lítico de la ocupación inicial (ca. 10.000 años AP) del sitio Cueva El Abra (Buenos Aires. Argentina). Relaciones de la Sociedad Argentina de Antropología XLIII (1): 87112.

2019 Raw material procurement and landscape use during the Pleistocene/Holocene transition in the eastern Tandilia Range (Buenos Aires, Argentina). PaleoAmerica 5 (1):62-72.

2020a Análisis de la organización de la tecnología lítica de los grupos cazadores-recolectores tempranos del área de Tandilia Oriental (Buenos Aires). Sociedad Argentina de Antropología, Buenos Aires.

2020b Lithic Technological Analysis of a New Archaeological Site (Cueva Alí Mustafá, 12,000 cal yr BP) of the Pleistocene/Holocene Transition in Eastern Tandilia, Buenos Aires, Argentina. PaleoAmerica 6 (3): 223-233.

Bonnat G. y D. Mazzanti

2015 Análisis de la tecnología lítica de las ocupaciones humanas efímeras durante la transición Pleistoceno- Holoceno: el caso de Cueva La Brava (Buenos Aires, Argentina). Intersecciones en Antropología 16: 287-300

Bonnat, G., D. Mazzanti y G. A. Martínez

2015 Tecnología lítica y contexto geoarqueológico de la ocupación temprana del Sitio 2 de la localidad arqueológica Amalia, provincia de Buenos Aires (Argentina). Revista del Museo de Antropología 8 (2): 21-32.

Bonomo, M. y A. Blasi.

2010 Base regional de recursos líticos del Delta del Paraná. Estudio petrográfico de artefactos y afloramientos en el sur de Entre Ríos. Cazadores-Recolectores del Conos Sur. Revista de Arqueología 4:17-41. 
Bonomo, M. y L. Prates

2014 La explotación de depósitos secundarios de rodados en el curso medio del Río Negro y el litoral Marítimo Pampeano. En Artefactos líticos, movilidad y funcionalidad de Sitios en Sudamérica. Problemas y Perspectivas (ed. por P. Escola y S. Hocsman), pp. 77-92. BAR International Series 2628, Oxford.

Brea, M., D. Mazzanti y G. A. Martínez

2014 Selección y uso de los recursos madereros en cazadores-recolectores de la transición Pleistoceno Holoceno y Holoceno medio, sierras de Tandilia oriental, Argentina. Revista del Museo Argentino de Ciencias Naturales Nueva Serie 16 (2): 129-141.

2020 Xerophytic Forest Record of the Pleistocene/Holocene Transition and Use of Wood Resources by Early Human Groups in the Eastern Tandilia Range, Argentina. PaleoAmerica (6): 234-249.

\section{Catella, L., J. Moirano y F. Oliva}

2010 Disponibilidad de materias primas líticas y su importancia para el análisis del uso del espacio y la organización de la tecnología en sociedades cazadoras recolectoras. En Mamül Mapu: pasado y presente desde la arqueología pampeana (ed. por M. Berón, L. Luna, M. Bonomo, C. Montalvo, C. Aranda y M. Carrera), pp. 239-253. Editorial Libros del Espinillo, Ayacucho.

\section{Catella L., A. Insaurralde y J. Angel}

2020 Disponibilidad de fuentes de aprovisionamiento y selección de materias primas líticas en el sudoeste de la provincia de Buenos Aires. Comechingonia. Revista de Arqueología. Vol. 24 (10): 1-29.

Civalero, M. y N. Franco.

2003 Early Human Occupations in Western Santa Cruz Province, Southernmost South America. Quaternary International 109-110: 77-86.

Colobig M., A. Zucol, A. Fabián, D. Mazzanti, G. A. Martínez y E. Passeggi.

2016 Registros biosilíceos en sitios arqueológicos de las sierras de Tandilia Oriental, Argentina (Pleistoceno Tardío-Holoceno Tardío): Consideraciones paleoambientales. Rev. Mus. Argentino Cienc. Nat., n. s.: 18 (1): 39-52.

Colombo, M.

2011 El área de abastecimiento de las ortocuarcitas del grupo Sierras Bayas y las posibles técnicas para su obtención entre los cazadores y recolectores pampeanos. Intersecciones en Antropología 12: 231-244 
Colombo, M. y N. Flegenheimer.

2013 La elección de rocas de colores por los pobladores tempranos de la región Pampeana (Buenos Aires, Argentina): Nuevas Consideraciones desde las canteras. Boletín del Museo Chileno de Arte Precolombino 18 (1): 125-137.

Ericson, J.

1984 Toward the analysis of lithic production systems. En Prehistoric Quarries and Lithic Production, (ed. por J. Ericson y Purdy), pp. 1-9. Cambridge University Press. Cambridge.

Flegenheimer, N.,

2004 Las ocupaciones de la transición Pleistoceno-Holoceno: una visión sobre las investigaciones en los últimos 20 años en la Región pampeana. Actas del X Congreso Nacional de Arqueología Uruguaya, 26-29 noviembre 2001. CD, (ed. por L., Beovide, I. Barreto y C. Curbelo). Uruguay.

Flegenheimer, N. y C. Bayón

1999 Abastecimiento de Rocas en Sitios Pampeanos Tempranos: Recolectando Colores. Los Tres Reinos: Prácticas de Recolección en el Cono Sur de América (ed. por C. Aschero, M. Kostanje y P. Vuoto), pp. 95-107. Instituto de Arqueología y Museo, FCNeIML-UNT, Ediciones Magna Publicaciones, Tucumán

Flegenheimer, N., S. Kain, M. Zárate y A. Barna 1996 Aprovisionamiento de rocas cuarcíticas en Tandilia. Las canteras del Arroyo Diamante. Arqueología 6: 117-143.

Flegenheimer, N., M. Zárate y M. Valente 1999 El área de canteras Arroyo Diamante, Barker, Sierras de Tandil. Actas XII Congreso Nacional de Arqueología Argentina (ed. por C. Diez Marín), Tomo III: 134-138. La Plata, Universidad Nacional de La Plata.

Flegenheimer N., C. Bayón y M. González de Bonaveri

1995 Técnica simple, comportamientos complejos: la talla bipolar en la arqueología bonaerense. Relaciones de la Sociedad Argentina de Antropología XX: 81-110.

Flegenheimer, N., C. Bayón, M. Valente, J. Femeninas y J. Valente.

2003 Long distance tool stone transport in the Argentine Pampas. Quaternary international 109110: 49-64. 
Flegenheimer, N., N. Mazzia y C. Weitzel.

2015 Landscape and Rocks in the East-Central Portion of the Tandilia Range (Buenos Aires Province, Argentina). PaleoAmerica Vol. 1 (2): 163-180.

Franco, N.

2004 La organización tecnológica y el uso de escalas espaciales amplias. El caso del sur y oeste de Lago Argentino. Temas de Arqueología, Análisis Lítico, (eds. A. Acosta, D. Loponte y M. Ramos), pp. 101-144. Universidad Nacional de Luján.

Geneste, M.

1988 Systemes d' approvisionnement en matieres premieres au paléolithique moyen et au paléolitique supérieur en Aquitaine. L 'Homme de Néandertal 8: 61-70.

Hogg, A., T. Heaton, Q. Hua, J. Palmer, C. Turney, J. Southon, A. Bayliss, P. Blackwell, G. Boswijk, B. Ramsey, C. Pearson, F. Petchey, P. Reimer, R. Reimer y L. Wacker

2020 SHCal20 Southern Hemisphere calibration, 0-55,000 years cal BP. Radiocarbon 62.

Inizan, M., M. Reduron-Ballinger, H. Roche, y J. Tixier 1995 Technologie de la pierre taillée. Préhistoire de la Pierre Taillée, 4. Cercle de Recherches et d'Etudes Préhistoriques, Francia.

Karlin, C.

1991 Connaissances et savoir-faire: comment analyser un processus technique en prehistoire introduction. Tecnología y Cadenas Operativas Líticas. Treballs d’Arqueologia I: 99-124.

Leipus, M.

2014 Estado Actual de las Investigaciones. El Sitio Arqueológico Arroyos Seco 2, Serie Monográfica 5 (ed. por G. Politis, M. Gutiérrez y C. Scabuzzo), pp. 229-273, INCUAPACONICET UNICEN. Olavarría.

Leroi-Gourhan, A.

1964 Le geste et la parole I- Technique et langage. Albin Michel, París.

Loponte, D., P. Tchilinguirian y R. Sacur Silvestre.

2010 Caracterización de afloramientos de calizas silicificadas de la provincia de Entre Ríos (Argentina) y su vinculación con los circuitos de abastecimiento prehispánico. Avances y Perspectivas en la Arqueología del Nordeste (ed. por M. Feuillet, M. Terzaghi, B. Colasurdo, J. Sartori y S. Escudero), pp. 125-139. Buenos Aires. 
Martínez, G.

2006 Arqueología del curso medio del río Quequén Grande: estado actual y aportes a la arqueología de la región pampeana. Relaciones de la Sociedad Argentina de Antropología XXXI: 249275.

Martínez, G., L. Prates, G. Flensborg, L. Stoessel, A. Alcaráz y P. Bayala.

2015a Radiocarbon trends in the Pampean region (Argentina). Biases and demographic patterns during the final Late Pleistocene and Holocene. Quaternary International 356: 89-110.

Martínez, G.A. y D.L. Mazzanti.

2017 Evidencia geoarqueológica de la transición Pleistoceno-Holoceno en reparos rocosos de Tandilia oriental (Provincia de Buenos Aires). Relaciones de la Sociedad Argentina de Antropología XLII: 83-106.

Martínez, G.A., Osterrieth, M. y D.L. Mazzanti

1999 Estratigrafía de sitios arqueológicos en reparos rocosos en las sierras de La Vigilancia y Valdés, sistema de Tandilia, provincia de Buenos Aires. Actas del XII Congreso Nacional Arqueología Argentina III: 139-144.

Martínez, G.A., D.L. Mazzanti, C. Quintana, A. Zucol, M. Colobig, G. Hassan, M. Brea y E. Passeggi.

2013 Geoarchaeological and Paleoenvironmental Context of the Human Settlement in the Eastern Tandilia Range, Argentina. Quaternary International. 299: 23-37.

Martínez, G. A., D.L. Mazzanti y M. Bernasconi.

2015b Procesos pedogenéticos en cuevas y aleros de Tandilia Oriental. Geoarqueologia na América do Sul, (ed. por J. Rubin, C. Dubois y R. Silva, pp. 109-140, Brasil, Editora da PUC Goiás.

Mazzanti, D.L.

1997 Archaeology of the Eastern edge of the Tandilia Range (Buenos Aires, Argentina). Quaternary of South America and Antartic Peninsula 10: 211-227.

1999 Ocupaciones humanas tempranas en Sierra La Vigilancia y Laguna La Brava, Tandilia Oriental, provincia de Buenos Aires. Actas del XII Congreso Nacional de Arqueología Argentina Tomo III, pp. 149-155. La Plata.

2003 Human Settlements in Caves and Rockshelters during the Pleistocene-Holocene Transition in the Eastern Tandilia Range, Pampean Region, Argentina. Where the south winds blow. Ancient Evidences for Paleo South Americans, (ed. por M. Salemme, N. Flegenheimer y L. Miotti), pp: 57-61. Center for the Studies of the First Americans (CSFA) and Texas University. 
2007 Arqueología de las relaciones interétnicas posconquista en las sierras de Tandilia, Tesis Doctoral Inédita, Universidad Nacional de Buenos Aires.

Mazzanti, D.L. y G. Bonnat

2013 Paisajes arqueológicos y cazadores-recolectores de la transición Pleistoceno-Holoceno. Análisis de las cuencas de ocupación en Tandilia oriental, Provincia de Buenos Aires, Argentina. Relaciones de la Sociedad Argentina de Antropología XXXVIII (2): 521-541.

Mazzanti, D.L., G. A. Martínez y C. Quintana.

2012 Early Settlements in Eastern Tandilia, Buenos Aires Province, Argentina: Archaeological Contexts and Site-Formation Processes. SOUTHBOUND. Late Pleistocene Peopling of Latin America. Special Edition (ed. por L. Miotti, M. Salemme, N. Flegenheimer y T. Goebel), pp. 115-119. Texas University.

Mazzanti, D.L., G. A. Martínez, M. Colobig, A. Zucol, E. Passeggi, M. Brea, G. Bonnat, G. Hassan, J. Soria, J. Vera y C. Quintana

2013 Avances en los estudios arqueológicos, geoarqueológicos y paleoambientales en las sierras de Tandilia. Resultados preliminares en Alero El Mirador y Abrigo La Grieta. Revista del Museo de La Plata, Sección Antropología 13 (87): 59-76.

Mazzanti, D.L., G. Bonnat, J.P. Donadei Corada y G.A. Martínez

2019 Cueva Alí Mustafá: un nuevo sitio arqueológico con ocupación temprana en las Sierras Orientales de Tandilia (Argentina). Arqueología 25 (2): 103-116.

Mazzia, N

2010 Lugares y Paisajes de Cazadores Recolectores en la Pampa Bonaerense: Cambios y Continuidades Durante el Pleistoceno Final - Holoceno. Tesis Doctoral Inédita. Facultad de Ciencias Naturales y Museo, Universidad Nacional de La Plata.

Meltzer, D.

1989 Was Stone Exchanged Among Eastern North American Paleoindians? Eastern Paleoindian lithic resource use, (eds. C. Ellis y J. Lothrop), pp. 11-39. Westview Press, Boulder.

Messineo, P. y P. Barros

2015 Lithic raw materials and modes of exploitation in quarries and workshops from the center of the pampa grasslands of Argentina. Lithic Technology 40 (1): 1-20. 
Nami, $\mathrm{H}$.

1991 Desechos de talla y teoría de alcance medio. Un caso de Península Mitre, Tierra del Fuego. Shincal 3:94-112.

2017 Silcrete as a valuable resource for stone tool manufacture and its use by Paleo-American hunter-gatherers in southeastern South America. Journal of Archaelogical Science: Reports 15: 539560.

Nelson, $\mathrm{M}$.

1991 The Study of technological organization. Archaeological Method and Theory 3:57-100.

Oliva, F. y J. Moirano

1997 Primer informe sobre aprovisionamiento primario de riolita en Sierra de La Ventana. Arqueología pampeana en la década de los '90. XI Congreso Nacional de Arqueología Argentina (ed. por M. Berón y G. Politis), pp. 137-146. San Rafael, Mendoza.

Pal, N., M., Barros, M. Gutiérrez y G. Martínez

2019 Modos de uso de la tecnología lítica durante el Holoceno temprano y medio : el caso del sitio Paso Otero 4 (Region Pampenana, Argentina). Chungara Revista de Arqueologia Chilena. 51(3): 325-337.

Pelegrin, J., C. Karlin, y P. Bodu.

1988 "Chaînes opératoires": un outil pour le préhistorien. Technologie préhistorique. Notes et Monographies techniques 25: 55-62.

Perlés, C.

1991 Économie de la matiere premiére et economie de debitage: deux exempls grecs. Prehistoire et technologie lithique. URA 28 du CRA Cahier 1, CNRS, Paris.

Pigeot, N.

2003 La economía de la talla de la piedra. Cazadores-recolectores de Ponsonby (Patagonia Austral) y su paleoambiente desde el VI al III milenio AC., (ed. por D. Legoupil), pp. 117-164. Universidad de Magallanes, Punta Arenas.

Politis G., M. Gutierrez y C. Scabuzzo

2014 Estado actual de las investigaciones en el sitio arqueológico Arroyo Seco 2. Serie Monográfica 5. INCUAAPA-CONICET. Facultad de Ciencias Sociales. UNCPBA. Olavarría.

Politis G., M. Gutierrez, D. Rafusen y A. Blasi.

2016 The Arrival of Homo sapiens into the Southern Cone at 14.000 Years Ago. PLOES ONE 28:1-28. 
Politis, G., P. Messineo, T. Stafford Jr. y E. Lindsey.

2019 Campo Laborde: A Late Pleistocene giant ground sloth kill and butchering site in the Pampas. Science Advances. 5 (3): 1-10.

Quintana C. y D. Mazzanti

2001 Selección y aprovechamiento de recursos faunísticos. Cueva Tixi, cazadores y recolectores de las sierras de Tandilia Oriental. Geología, Paleontología y Zooarqueología, (ed. por D. Mazzanti y C. Quintana), pp. 181-209. Facultad de Humanidades, Universidad Nacional de Mar del Plata. Publicación especial 1.

Quintana, C., G. A. Martínez, M. Osterrieth y D. Mazzanti.

2001 Mammal Footprints in a Cave on the Eastern Edge of Tandilia Range, Late Plaistocene of Buenos Aires Province, Argentina. Current Reseach in the Pleistocene 18: 110-111. Arizona.

Rafuse D. y A. Massigoge

2020 Abrigo La Tinta: Preliminary Results of a New Late Pleistocene-Early Holocene Rockshelter from the Pampas Region (Tandilia Range), Argentina. PaleoAmerica 6 (3): 229-301.

Stuiver, M., P.J. Reimer y R.W. Reimer.

2020 CALIB 7.1 Radiocarbon Calibration (program). http://calib.org.

Tixier, J. M-L Inizan y H. Roche.

1980 Préhistouire de la Pierre taillée I. Terminologie et technologie. Centre de recherches et d'études préhistoriques. Paris

Teruggi, M., J. Kilmurray, C. Rapela y L. Dalla Salda.

1974 Diques básicos en las Sierras de Tandil. Revista de la Asociación Geológica Argentina XXIX (1): 41-60.

Vecchi, R.

2016 Materias primas líticas de bolas de boleadora del sector bonaerense de la Región Pampeana. Relaciones de la Sociedad Argentina de Antropología XLI: 191-215. 